\title{
Projeto E-book Cederj: Proposta, Metodologia de Execução E Análise Inicial de Resultados
}

\author{
Luciana Tavares Perdigão*1, Samira Pirola Santos Mantilla², Daniel Fábio \\ Salvador ${ }^{3}$
}

\begin{abstract}
${ }^{1}$ Designer Instrucional e Pesquisadora, Departamento de Mídias Digitais/Fundação Cecierj. Rua da Ajuda, $\mathrm{n}^{\circ} 5,15^{\circ}$ andar, Centro - Rio de Janeiro - RJ - Brasil. Iperdigao@cecierj.edu.br

2 Designer Instrucional e Pesquisadora, Departamento de Mídias Digitais/Fundação Cecierj. Rua da Ajuda, $\mathrm{n}^{\circ} 5,15^{\circ}$ andar, Centro - Rio de Janeiro - RJ - Brasil. smantilla@cecierj.edu.br

3 Professor e Pesquisador, Departamento de Mídias Digitais/Fundação Cecierj. Rua da Ajuda, $\mathrm{n}^{\circ} 5,5^{\circ}$ andar, Centro - Rio de Janeiro - RJ - Brasil. salvador@cecierj.edu.br
\end{abstract}

\section{Resumo}

O Projeto E-book Cederj foi desenvolvido na Fundação Cecierj e consiste num sistema dinâmico que transforma os cadernos didáticos impressos em livros digitais que podem ser enriquecidos de recursos multimídia e atividades na plataforma Moodle sugeridos pelos professores dos cursos de graduação. O objetivo da pesquisa foi apresentar e analisar o processo de criação do E-book, bem como o volume de recursos multimídia utilizados na fase piloto do Projeto para os diversos cursos de graduação a distância do Consórcio Cederj. As categorias de recursos multimídia utilizadas no Projeto foram: animação, atividade, arquivo, áudio, fórum, imagem, site, texto e vídeo. Observa-se que houve um aumento de $65 \%$ de recursos adicionados do mês de setembro até o mês de novembro. Os recursos mais utilizados nos E-books foram a animação (37\%), seguida pelo site (22\%) e pelo vídeo (19\%). O Projeto tem encontrado forte adesão dos coordenadores de disciplina do Consórcio Cederj bem como expande possibilidades para integração didática de diferentes mídias e plataformas sempre mantendo a autonomia do professor.

Palavras-chave: E-Book; Multimídia; Livros didáticos; Animações. 


\title{
E-book Cederj Project: Proposal, Implementation Methodology and Initial Analysis of Results
}

\begin{abstract}
The E-book Cederj Project was developed by a team of experts from the Department of Digital Media at Cecierj Foundation and consists of a dynamic system that transforms the didactic books into digital books and can be improved with multimedia features and Moodle activities which are suggested by teachers from each degree course. The research objective was to present the process of e-book creation and analyze the amount available multimedia resources in E-books for undergraduate courses e-learning at the Cederj Consortium. The types of multimedia resources are: animation, file, activity, audio, forum, picture, website, text, and video. We note that there was an $65 \%$ increase of features added in the month of September to November. The resources most commonly used in E-books were animation with $37 \%$, followed by site $(22 \%)$ and video $(19 \%)$. The project has support from the Cederj discipline coordinators, and it is expanding opportunities for didactic integration of different media and platforms, while maintaining the autonomy of the teacher.
\end{abstract}

Keywords: E-Book; Multimedia; Didactics books; Animations. 


\section{Introdução}

"Um dos piores erros que uma organização ou instrutor pode cometer é se restringir dogmaticamente a uma única mídia." MOORE (2007).

Segundo o Horizon Report de 2011 (Johnson et al., 2011), os e-books estão começando a demonstrar a capacidade de desafiar a própria definição de leitura. Elementos audiovisuais, interativos e sociais aprimoram o conteúdo dos livros e revistas, e ferramentas sociais estendem a experiência do leitor para um mundo mais amplo, conectando leitores e permitindo explorações mais profundas e colaborativas do texto. Deixando de ser uma mera reprodução digital de uma obra impressa, as novas interfaces transportam a experiência de leitura com interações táteis a uma nova esfera. Para Epstein (2002), como as tecnologias da linguagem oral, da escrita e dos dispositivos móveis, essas tecnologias eletrônicas irão alterar radicalmente o modo de transmissão de informações, de leitura, de histórias e de formação de cultura.

Nesse sentido, elas tendem naturalmente a ser incorporadas como referências ao trabalho do professor em EaD, e dispositivos de computação móvel, como Kindle, iPad etc., tendem a constituir uma nova categoria de plataformas em relação aos Ambientes Virtuais de Aprendizagem - AVA (Mattar, 2012).

O Projeto E-book Cederj consiste em disponibilizar os cadernos didáticos dos cursos de graduação semipresencial do Consórcio Cederj no formato digital para acesso via dispositivos móveis pelos alunos, enriquecendo-os com recursos multimídia e atividades, sugeridos não só nos próprios livros digitais, como também atualmente publicados pelo professor no AVA Moodle, além de outros materiais complementares selecionados. O diferencial do Projeto E-book Cederj é que ele possui um sistema dinâmico de administração dos recursos multimídia inseridos, dando total autonomia ao professor para incluir e retirar recursos, mesmo após a sua publicação para os alunos, com atualização constante em tempo real.

O Consórcio Cederj coordena a graduação a distância de oito universidades públicas de ensino superior: CEFET, UERJ, UFRJ, UFRRJ (Rural), UFF, UNIRIO, UENF. Ao final do curso de graduação, o aluno recebe o diploma de uma dessas instituições, da mesma forma que um aluno que cursa presencialmente. A modalidade de ensino é 
semipresencial e existem 32 polos Cederj distribuídos pelo estado do Rio de Janeiro. Por meio desse Consórcio, muitos alunos que trabalham ou residem longe dos centros urbanos podem estudar em uma universidade pública, obtendo um diploma conceituado para atuar no mercado de trabalho. Os cursos oferecidos possuem uma plataforma de ensino a distância que disponibiliza recursos e materiais de estudo para os alunos. A criação do Projeto E-book veio suprir a necessidade de oferecer mais uma forma de acesso aos conteúdos abordados nos cursos, permitindo a visualização em dispositivos móveis.

Na Figura 1, observa-se um exemplo de um E-book do curso de Biologia, visualizado a partir de um dispositivo móvel (Samsung Galaxy Tab4).

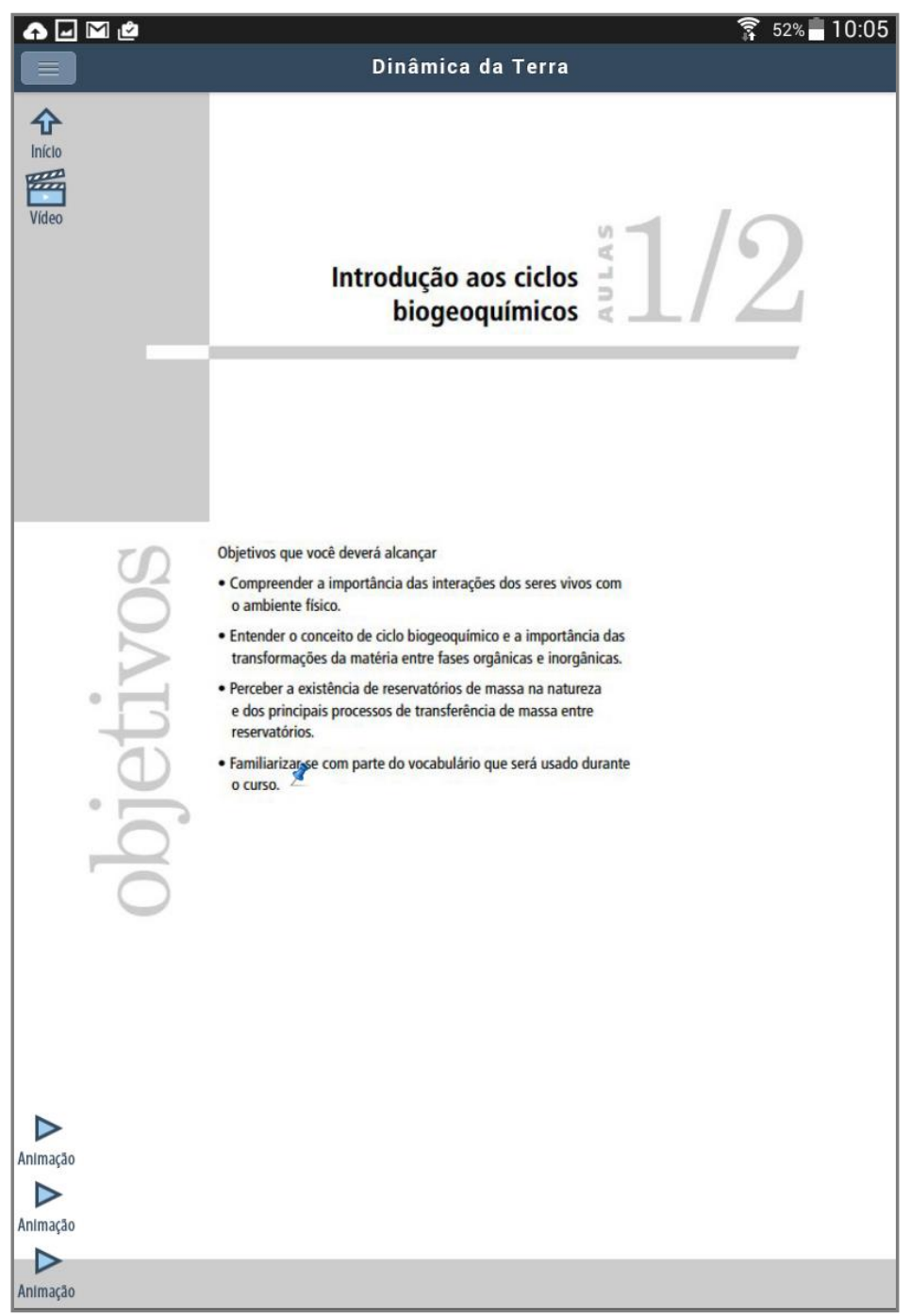

Figura 1 - Exemplo de um E-book do curso de Biologia. 
O objetivo do presente estudo é apresentar o processo de criação do Projeto Ebook Cederj e analisar os resultados iniciais durante a fase piloto em relação aos recursos multimídias disponibilizados nos E-books dos cursos de graduação do Consórcio Cederj.

\section{Metodologia}

Os processos de criação do E-book bem como as interfaces de usuário final e administrativas do sistema são apresentados nos resultados deste trabalho de forma descritiva com imagens ilustrativas.

A análise da fase inicial Projeto E-book Cederj foi realizada por meio de gráficos gerados a partir de relatórios obtidos no próprio sistema. Foram elaborados gráficos quantitativos que apresentam o volume de recursos, os cursos e os e-books produzidos entre os meses de setembro, outubro e novembro de 2014. Além disso, foram gerados gráficos comparativos que demonstram qual curso explora mais recursos e qual a categoria de recurso mais utilizada pelos diferentes cursos de graduação.

\section{Resultados e discussão}

A escolha das disciplinas que entram no Projeto E-book Cederj é baseada nos seguintes critérios: número de recursos multimídia já oferecidos pela disciplina (quanto maior o número de recursos, mais rico será o E-book da disciplina) e se a disciplina possui o caderno didático como parte central dela (evitando-se disciplinas sem caderno didático atualizado).

Para a elaboração dos E-books Cederj a equipe do Departamento de Mídias Digitais realiza a sequência de ações descritas a seguir:

1. O Designer instrucional (DI) responsável pela área, em colaboração com coordenadores de curso, seleciona as disciplinas com potencial para o Projeto Ebook;

2. O DI se comunica com os coordenadores de disciplina sobre o Projeto, solicitando a permissão para elaborar o E-book para aquela disciplina; 
3. O DI solicita à equipe de web designers a criação das disciplinas no sistema Ebook através do upload dos arquivos em pdf;

4. O tutor de apoio ao professor $(\mathrm{TAP})^{1}$ ou o próprio professor inicia a inclusão na página administrativa do Projeto (Figura 2):

a. Primeiramente dos recursos que já estão na plataforma;

b. Depois, de recursos adicionais para enriquecimento do E-book.

5. Após o término do trabalho, o material passa por revisão final do coordenador de disciplina, sendo aprovado para publicação;

6. O DI libera a versão 1 para o aluno com atualizações constantes pelo professor da disciplina a partir desse momento.

Os recursos incluídos no E-book são basicamente links de diversos tipos de materiais publicados na web: textos, arquivos em diferentes formatos, animações e vídeos, além de recursos idealizados pelo professor ou DI e produzidos pela equipe do Departamento de Mídias Digitais.

Podem ser incluídos também materiais publicados pelo professor na plataforma, assim como atividades, tais como fóruns e questionários permanentes, que não se alterem com facilidade de um semestre para o outro e que tenham conexão com o caderno didático. Por exemplo, um fórum para discutir tabagismo, relacionado à página XX da aula sobre sistema respiratório, ou um questionário no Moodle com perguntas sobre alguma aula. No Quadro 1, observam-se os tipos de recursos que podem ser incluídos no E-book e suas características.

\begin{tabular}{|l|l|}
\hline & $\begin{array}{l}\text { Sequência de imagens (vídeos, fotos, ilustrações), com ou sem som, } \\
\text { utilizadas para simular uma situação. Diferente do vídeo, que o aluno } \\
\text { anenas o assiste, a animação oferece a possibilidade de interação. As } \\
\text { extensões mais usadas são .swf, .gif e html. Vídeos animados em 2D } \\
\text { ou 3D são considerados animação, mesmo que estejam em formato } \\
\text { MP4. }\end{array}$ \\
\end{tabular}


Documento para o aluno fazer download. Pode aparecer em vários formatos diferentes.

Link direto para alguma atividade da Plataforma Cederj (tarefa, questionário, wiki, lição etc.), caso tenha relação direta com o conteúdo do caderno didático. Atividade publicada na web fora da plataforma (por exemplo, uma webquest) pode também ser classificada aqui.

Atividade

Link para áudio publicado na internet. Caso não se encontre o arquivo original do áudio para incluir, pode-se fornecer o endereço do site que o aluno deve acessar para ouvir o áudio.

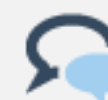
Link direto para a ferramenta fórum da plataforma Moodle Cederj, caso esse fórum tenha relação direta com algum conteúdo do caderno didático.
Fórum
م
Arquivo estático que pode ser ilustração, gráfico ou fotografia. As Imagem extensões mais usadas são: .jpg, .bmp, .png, .gif .
Página de informações na web, tipo hipertexto, blog etc., para acesso externo à plataforma. Vários dos demais recursos também são links da $w e b$, porém, aqui estamos nos referindo especificamente a páginas da web com conteúdo digital publicado.
Link da internet para algum texto, normalmente, em .pdf ou .doc. Esses textos podem também estar publicados na própria sala de aula virtual da disciplina na plataforma, e pode-se colocar o link direto da publicação. Para fazer referência a um texto ou hipertexto de um blog na web, deve-se usar a categoria "Site", e não "Texto".




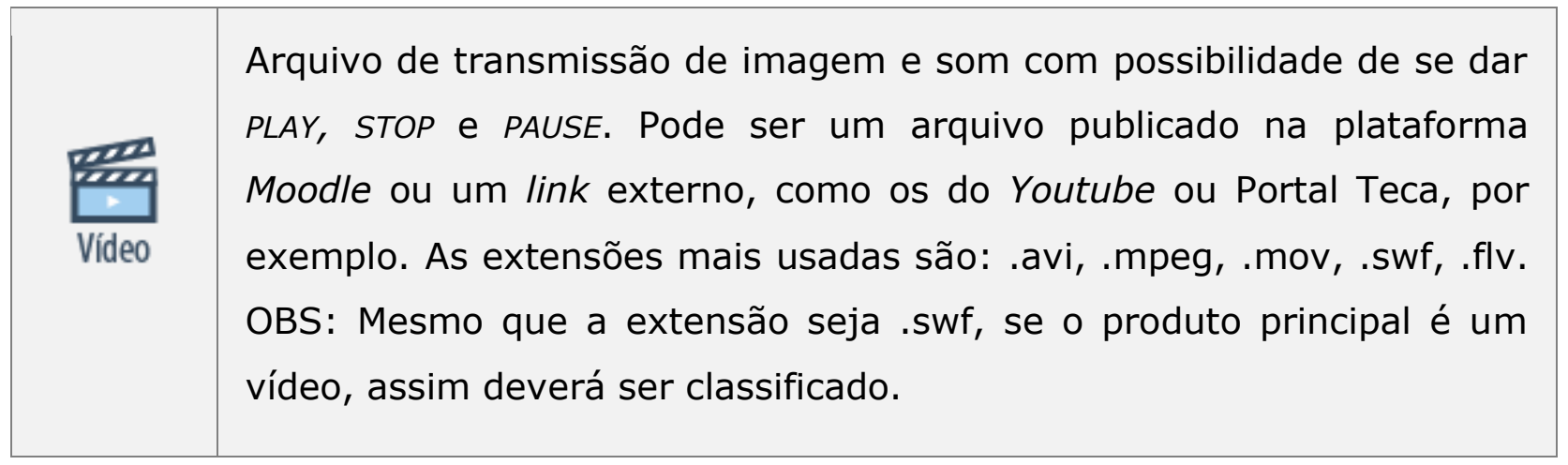

Quadro 1 - Tipos de recursos inseridos no E-book e suas descrições.

Na fase piloto do Projeto (meses de setembro, outubro e novembro de 2014) foram selecionadas 91 disciplinas, sendo que 47 delas já possuíam recursos inseridos no momento do levantamento dos dados deste trabalho (dados de novembro de 2014). A meta para 2015 é atingir 200 disciplinas com pelo menos cinco a seis recursos por aula (total de 10.000 recursos selecionados e inseridos no sistema).

Na Figura 2, é possível observar a página administrativa do sistema E-book. Nela, o professor pode inserir, editar e excluir recursos além de administrar os projetos, os cursos, os materiais e os usuários e gerar diversos relatórios.

Esse sistema de inclusão é um diferencial do Projeto E-book Cederj, visto que os professores podem atualizar o E-book de sua disciplina de forma simples, dinâmica e intuitiva, a partir do computador ou até mesmo de um dispositivo móvel. A atualização com a versão disponibilizada para os alunos é imediata se o acesso do aluno estiver sendo feito on-line, ou acontecerá na próxima conexão do tablet do aluno à internet, no caso da versão off-line do sistema. 


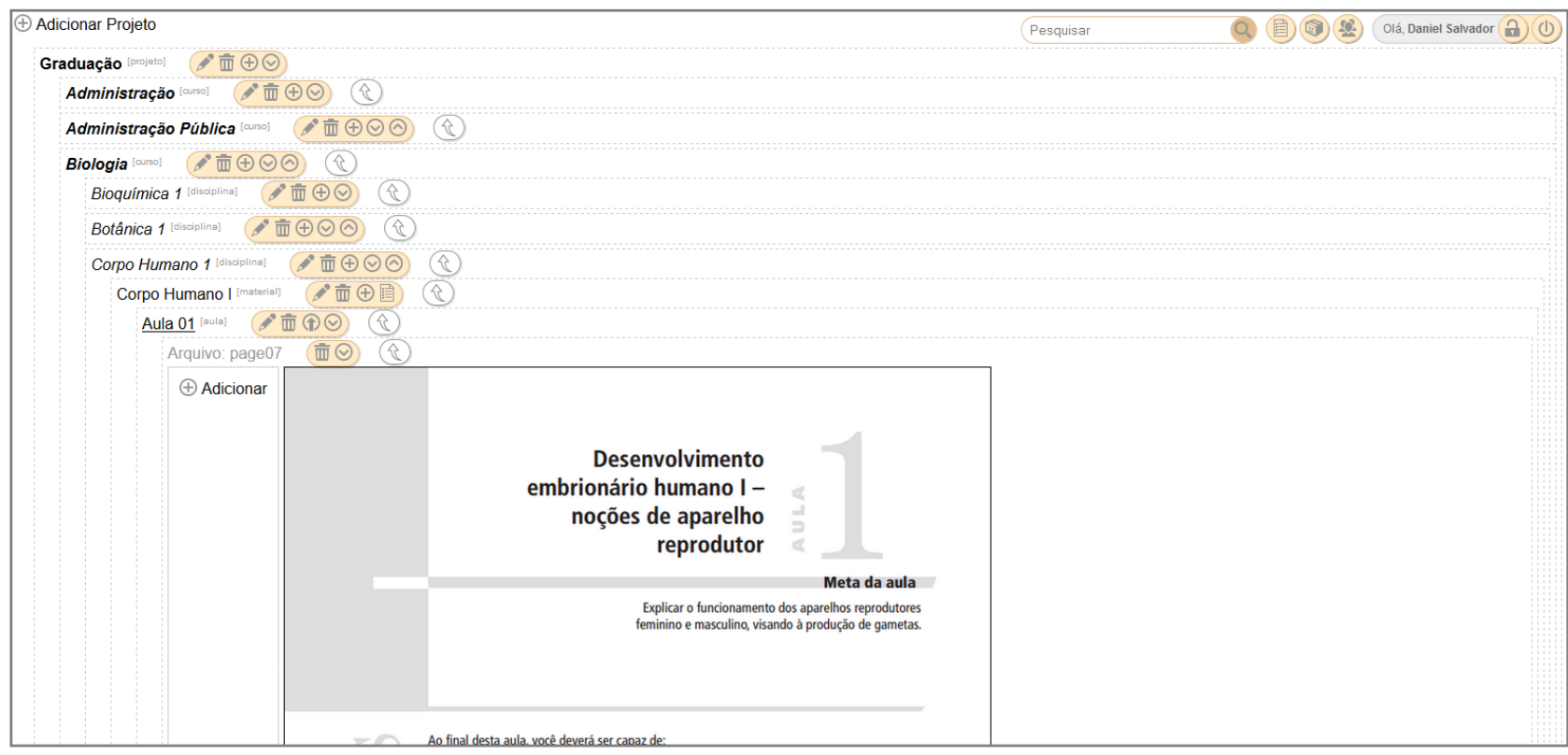

Figura 2 - Sistema de inclusão de recursos no E-book.

Quando o TAP ou o professor clicar no ícone (+) Adicionar, abre-se o Box "Adicionar recurso" que apresenta os campos necessários para preenchimento e a lista de categorias (Figura 3).

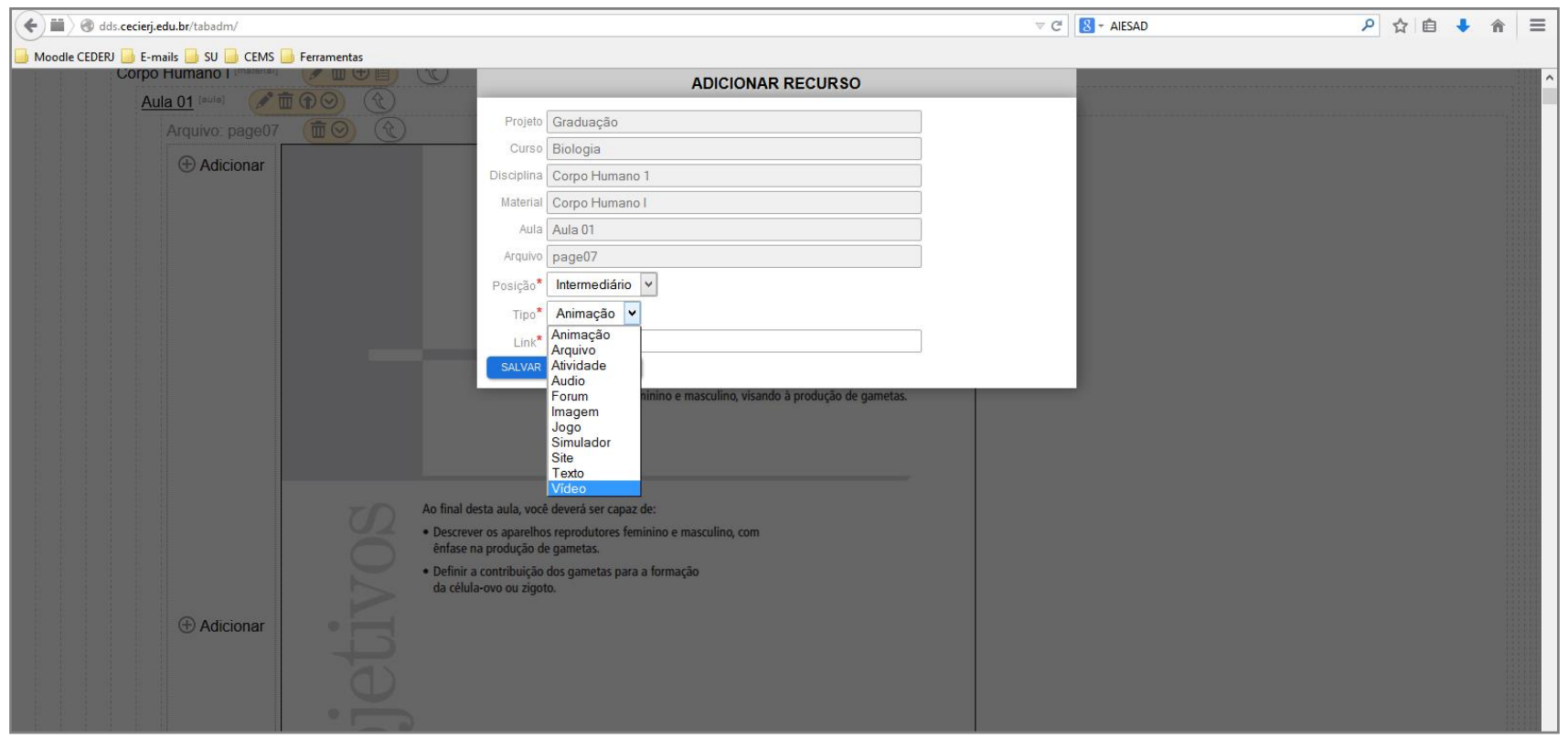

Figura 3 - Adicionando recursos: opção de tipo de recurso. 
A visualização do E-book pelo aluno através de um dispositivo móvel é apresentada na Figura 4. Observa-se que o menu com o índice remissivo é retrátil possibilitando uma navegação sem atrapalhar a legibilidade do conteúdo. Dessa forma, o aluno pode acessar qualquer capítulo do conteúdo através de apenas um toque.
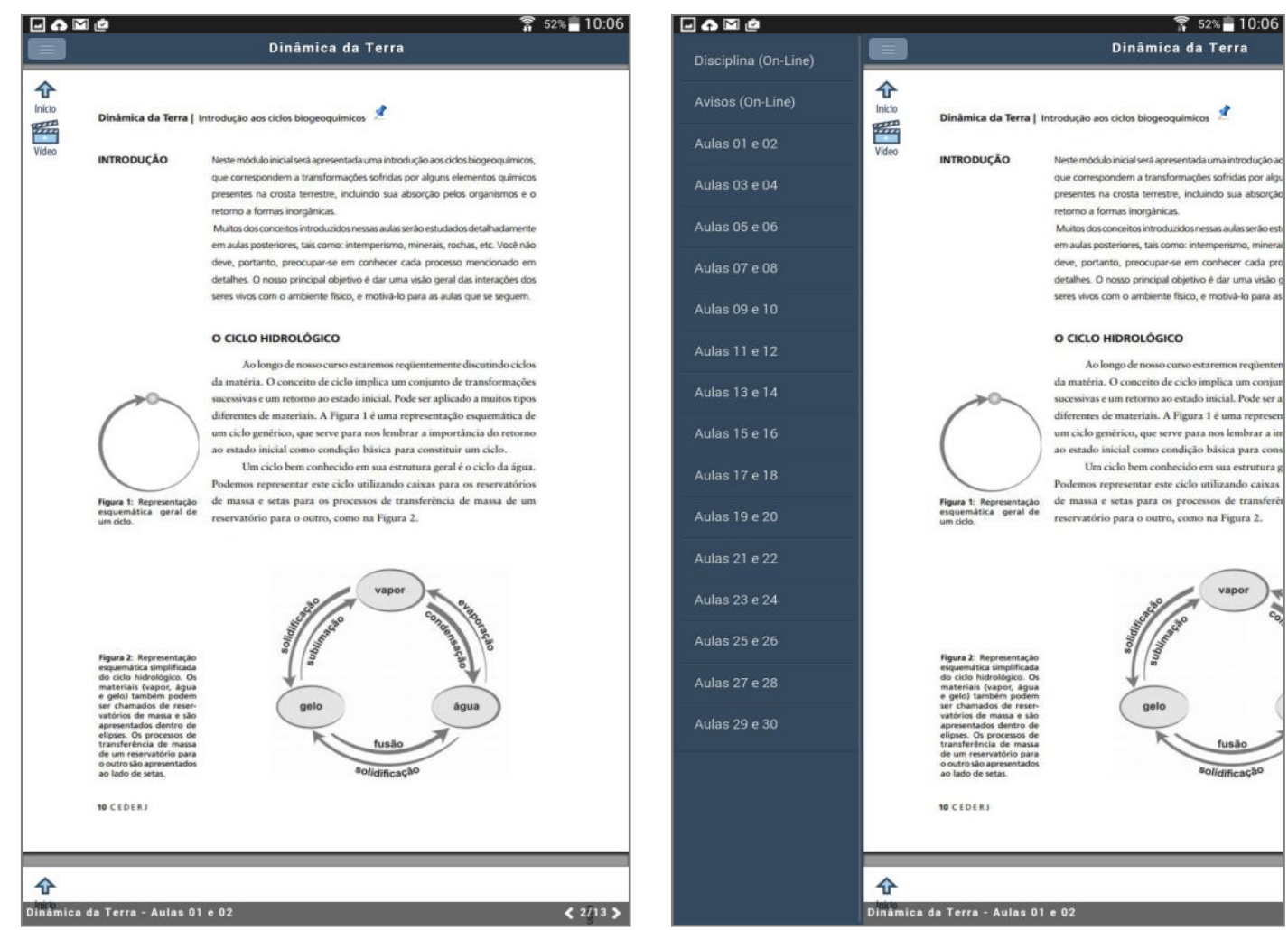

Figura 4 - Tela de visualização para o aluno.

Nas Figuras 5 e 6, consta o número de recursos (total e por categoria) adicionados ao longo dos meses de setembro, outubro e novembro de 2014.

Observa-se que houve um aumento de $65 \%$ de recursos adicionados do mês de setembro até o mês de novembro. Esse fato ocorreu por um trabalho intensivo da equipe de suporte (DIs e TAPs) no apoio aos coordenadores de disciplina, estimulados a buscar recursos na internet para enriquecer o E-book das disciplinas do Projeto durante esses meses. 


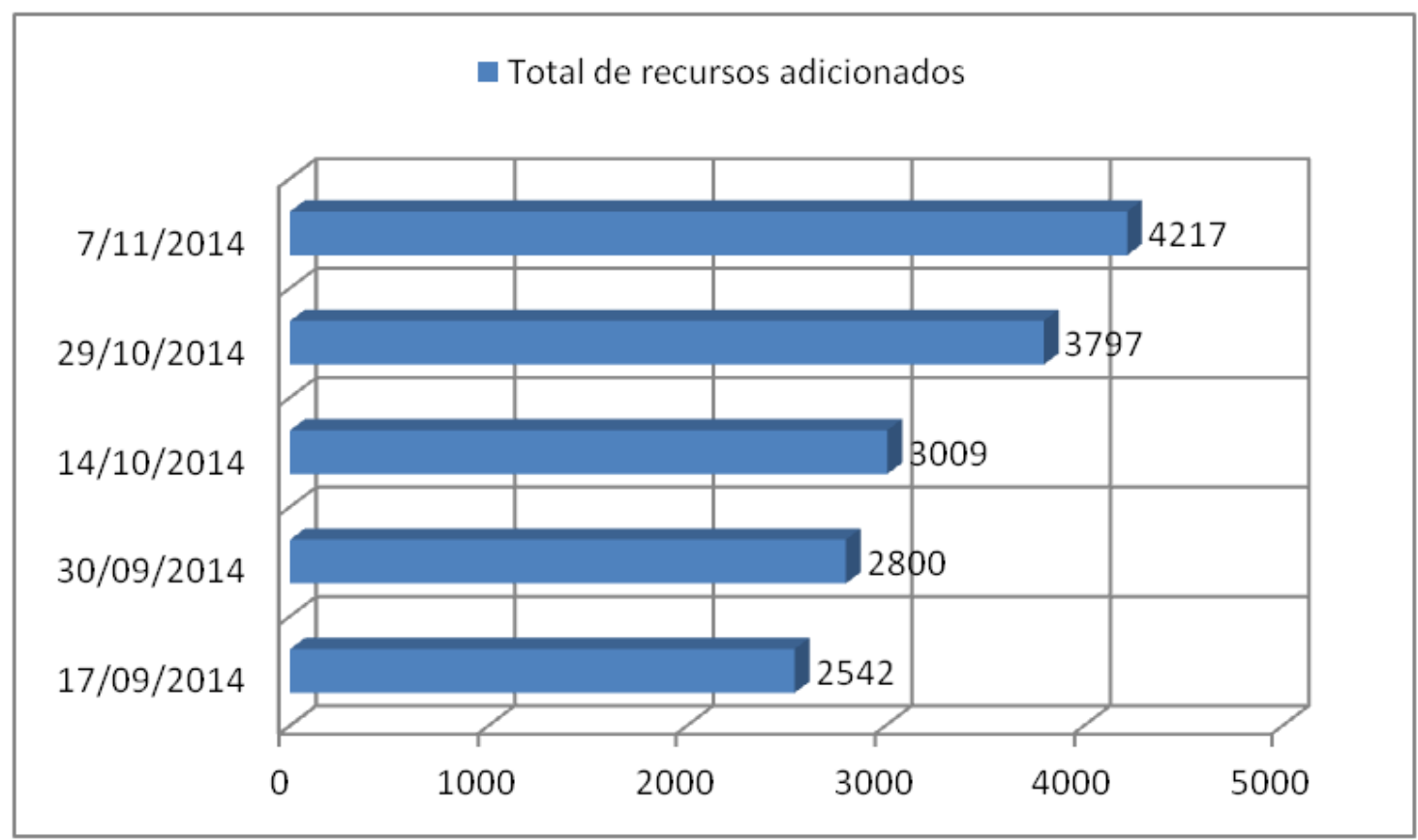

Figura 5 - Total de recursos adicionados ao longo dos meses de setembro, outubro e novembro de 2014.

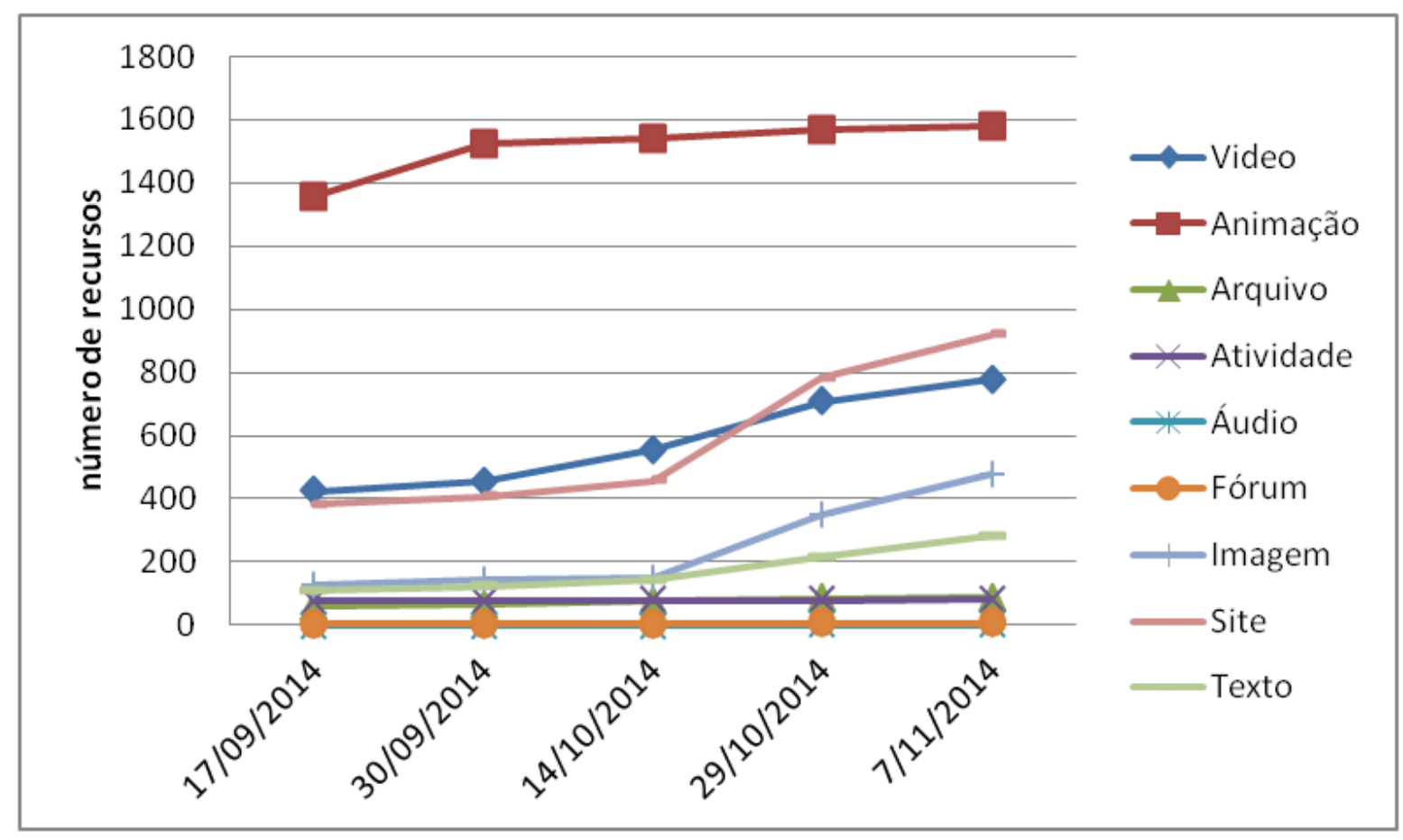

Figura 6 - Crescimento de recursos por categorias adicionados ao longo dos meses de setembro, outubro e novembro de 2014. 
Quadro 2: Projeto E-book - Relatório de Inclusão de Recursos

\begin{tabular}{|c|c|c|c|c|c|c|c|c|c|c|c|c|c|c|c|c|c|}
\hline \multicolumn{2}{|c|}{ Vídeo } & \multicolumn{2}{|c|}{ Animação } & \multicolumn{2}{|c|}{ Site } & \multicolumn{2}{|c|}{ Atividade } & \multicolumn{2}{|c|}{ Fórum } & \multicolumn{2}{|c|}{ Áudio } & \multicolumn{2}{|c|}{ Arquivo } & \multicolumn{2}{|c|}{ Imagem } & \multicolumn{2}{|c|}{ Texto } \\
\hline $17 / 09$ & $19 / 11$ & $17 / 09$ & $19 / 11$ & $17 / 09$ & $19 / 11$ & $17 / 09$ & $19 / 11$ & $17 / 09$ & $19 / 11$ & $17 / 09$ & $19 / 11$ & $17 / 09$ & $19 / 11$ & $17 / 09$ & $19 / 11$ & $17 / 09$ & $19 / 11$ \\
\hline 425 & 838 & 1356 & 1719 & 383 & 1026 & 75 & 82 & 3 & 7 & 0 & 1 & 61 & 92 & 127 & 494 & 112 & 309 \\
\hline
\end{tabular}

Analisando a Figura 6 e o Quadro 2, verifica-se um aumento do número de recursos inseridos ao longo dos meses de setembro a novembro de 2014. O recurso mais explorado nas inclusões foi a imagem com um aumento $275 \%$. Outros recursos que tiveram aumentos significativos foram texto $(152 \%)$, site (140\%) e vídeo ( $82 \%)$. Os recursos de áudio e fórum não tiveram aumentos significativos. O recurso que está em maior número nos E-books, nessa fase inicial do Projeto, são as animações com 1577 recursos incluídos.

Acredita-se que esse aumento da utilização dos recursos de imagem e vídeo deve-se ao fato de que, na web, aumenta-se cada vez mais o número de repositórios de recursos educacionais abertos e neles os recursos de imagem e vídeo são os que têm maior volume de arquivos. Além disso, a web possui hoje diversos canais de streaming de vídeo, como YouTube, que cada vez mais vêm sendo explorados na área educacional.

O vídeo foi um dos recursos de destaque tanto em relação ao volume global de publicações (19\%) quanto ao índice de crescimento de inclusões (82\%), na fase inicial do Projeto, já citado anteriormente. Esse recurso explora o som e imagem em movimento, aumentando as possibilidades de compreensão do conteúdo, porém sem interação. De acordo com Mattar (2009), o crescimento do fenômeno de vídeos baseados na web, do qual o YouTube é um ícone, ampliou o repositório de conteúdo livre que pode ser utilizado em EaD. Nunca foi tão fácil localizar, produzir e distribuir vídeos on-line. Isso abre interessantes possibilidades para o ensino, o aprendizado e o design de cursos presenciais e a distância.

Arquivos e atividades tiveram baixo índice de crescimento $(42,6 \%$ e 7,3\% respectivamente) em relação aos recursos citados anteriormente. Os recursos menos 
utilizados foram os fóruns, com a inclusão de apenas sete recursos, e áudio, com apenas um.

O fórum é uma ferramenta da plataforma Moodle que pode ser disponibilizada no E-book por meio de um link. É praticamente uma exclusividade do Consórcio Cederj explorar esse tipo de recurso nos seus livros digitais. O fórum pode ser explorado para ampliar as discussões sobre um tópico de forma colaborativa, incentivando a participação do aluno no processo de construção do conhecimento dentro do AVA da disciplina. Acreditamos que essa ferramenta do AVA, conectada aos conteúdos específicos do E-book, pode tornar-se ainda mais atrativa ao aluno. É importante frisar que o DI responsável vem estimulando o professor a utilizar o fórum na sala de aula virtual (AVA) para que os alunos possam desfrutar dos benefícios dessa ferramenta interativa, porém sua integração com o E-book dinâmico da disciplina ainda não tem sido largamente explorada.

Já o áudio é um recurso que poderia ser usado, por exemplo, por meio de podcasts, entrevistas e músicas. Entretanto, ainda é pouco explorado pelos professores da graduação do Cederj, mesmo em sala de aula, talvez pelo desconhecimento do uso pedagógico do recurso.

Nas Figuras 8 e 9, constatamos resultados da distribuição dos recursos por categoria em todos os cursos de graduação e o percentual de recursos multimídias disponibilizados nos E-books dos diferentes cursos de graduação do Consórcio Cederj, respectivamente. 


\section{Distribuição dos Recursos}

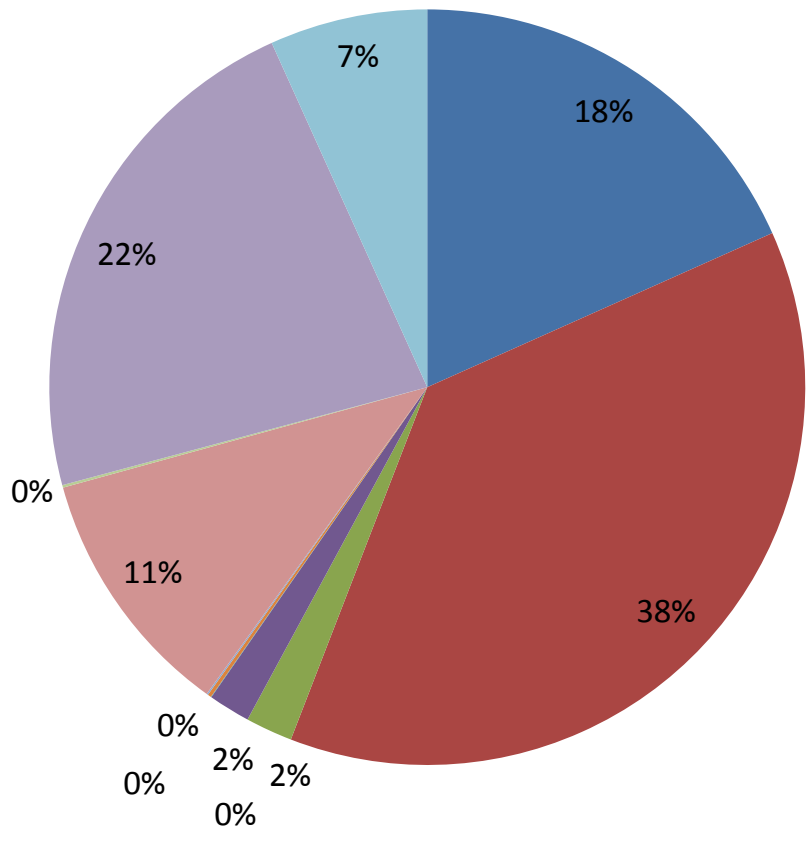

Vídeo

- Animação

- Arquivo

Atividade

Áudio

Fórum

- Jogo

- Imagem

Simulador

- Site

Texto

Figura 8 - Distribuição dos recursos por categoria em todos os cursos de graduação do Consórcio Cederj no mês de novembro de 2014.

Os recursos mais utilizados nos E-books nos cursos de graduação foram a animação com 37\% (Figura 8 ), seguida pelo site (22\%), vídeo (19\%) e imagens (11\%). Em consulta no mesmo mês (novembro de 2014) ao portal oficial do MEC de recursos multimídia (http://portaldoprofessor.mec.gov.br), resultados semelhantes foram achados, 70\% dos recursos desse portal sendo animações, vídeos e imagens com maior destaque para animações e vídeos.

O percentual de animações inseridas na fase piloto do E-book deve-se especialmente ao forte trabalho de produção multimídia desses recursos realizado pela fundação CECIERJ, entre os anos de 2003 a 2011, especialmente, para cursos como o de Ciências Biológicas, Matemática, Física e Pedagogia. As disciplinas que tinham esse material produzido foram eleitas inicialmente como potenciais disciplinas para o Projeto E-book e foi realizada a inserção automática (sem a necessidade de busca na web) desses objetos de aprendizagem multimídia publicados no portal TECA (http://teca.cecierj.edu.br/) pelo Consórcio CEDERJ, fato esse que influencia, portanto, os gráficos das figuras 9 e 10. 


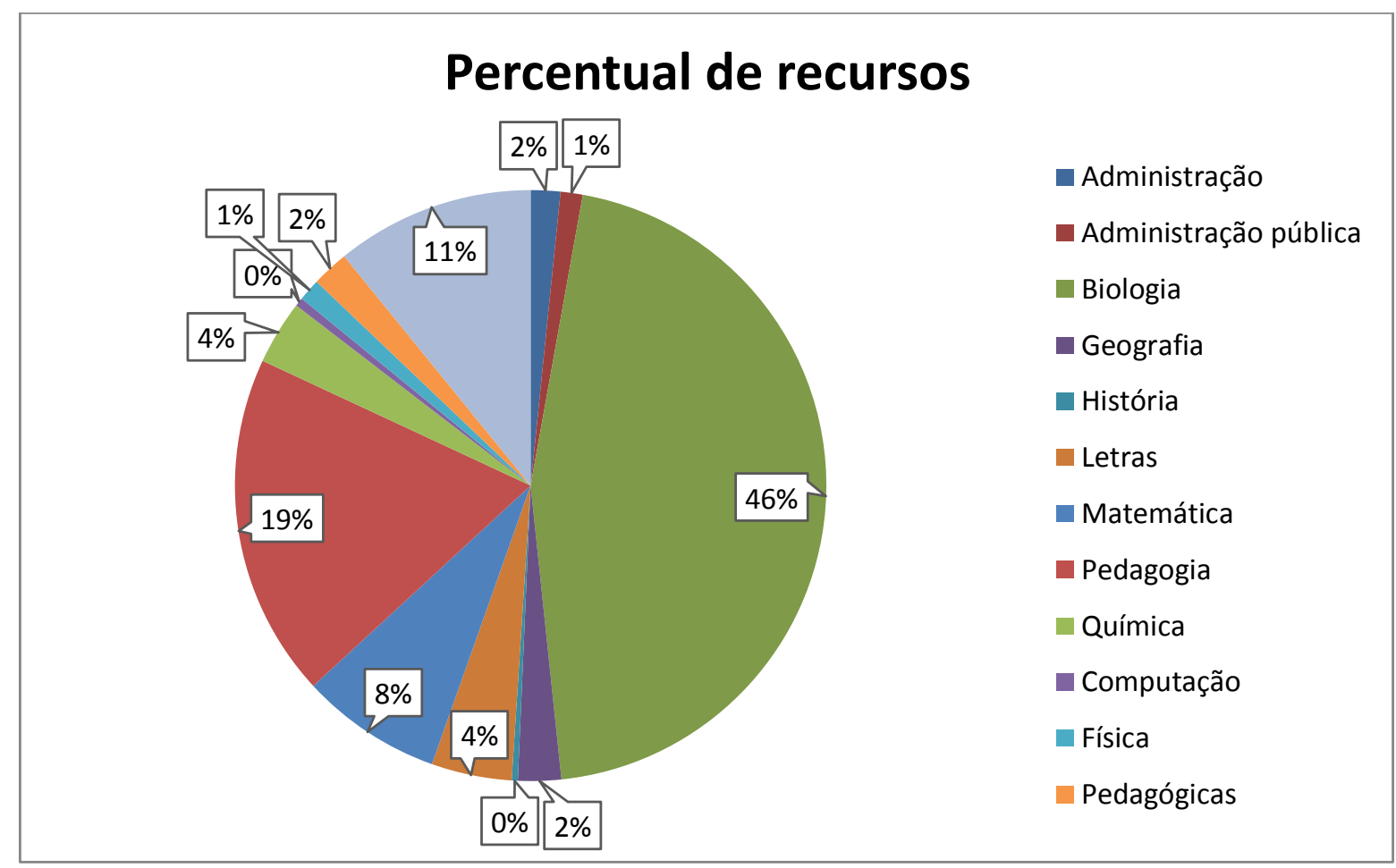

Figura 9 - Percentual de recursos multimídias disponibilizados nos E-books dos diferentes cursos de graduação do Consórcio Cederj.

Na Figura 9, observa-se que o curso de Biologia apresentou o maior percentual de recursos inseridos no E-book. Como já citado, isso ocorreu pois diversas disciplinas da Biologia se destacaram inicialmente por ter havido um trabalho intensivo de produção própria de recursos multimídia pelo Cederj nesse curso durante oito anos (2003 a 2011). Entretanto, nos últimos três anos, o Departamento de Mídias Digitais do Consórcio Cederj tem transformado sua filosofia de apoio às disciplinas quanto ao uso, seleção e produção de Recursos Educacionais Abertos (Mantilla, Fonseca, Alves, Perdigão \& Salvador no prelo), trazendo maior foco na seleção e reutilização de recursos abertos ao invés da produção efetiva desses recursos, o que foi também fator gerador da ideia de criação desse Projeto de E-book dinâmico.

\section{Considerações finais}

$\mathrm{Na}$ fase piloto do Projeto E-book Cederj, houve um aumento significativo de recursos explorados no sistema. Isso se deve ao fato de que as equipes de TAPs, DIs e 
professores ficaram empenhadas nos meses de setembro, outubro e novembro na inclusão de recursos para atingir a meta do Consórcio Cederj.

As animações, vídeos, sites e imagens se destacaram com o aumento do número de recursos inseridos nos E-books dos cursos de graduação do Consórcio Cederj. Já os áudio, fórum e atividades ainda são pouco explorados devido ao conhecimento insuficiente da utilização pedagógica desse tipo de recurso.

Destaca-se com um dos principais desafios enfrentados na fase piloto que, apesar de as animações serem um dos mais importantes recursos multimídia para esse tipo de projeto, a maior parte dos repositórios da web ainda as publicam na sua extensão em flash (swf), formato esse não compatível com tablets e dispositivos móveis. Para as animações produzidas na Fundação Cecierj, estamos buscando realizar a conversão desse material para HTML5, porém para recursos selecionados na web, isso ainda é um fator técnico limitador.

É importante salientar que o Projeto E-book foi idealizado no ano de 2013 e está em andamento, assim, espera-se que o número de recursos multimídias inseridos nesse livro digital aumente, visto que os professores estão sendo cada vez mais estimulados pelos designers instrucionais de cada curso para selecionar diferentes recursos na web com o intuito de enriquecer o livro digital de sua disciplina.

Além disso, o sistema do Projeto E-book é acompanhado constantemente pela equipe de programação, desenvolvendo modelos e aprimorando formatos para que a leitura digital torne-se uma experiência que venha atender a novas necessidades e usos para os livros digitais.

Apesar de estar ainda em sua fase piloto, o Projeto E-book dinâmico do CEDERJ vem encontrado forte adesão dos coordenadores de disciplina do Consórcio CEDERJ bem como expandindo possibilidades para integração didática de diferentes mídias e plataformas, porém, mesmo assim, mantendo a autonomia do professor. Ressalta-se a necessidade crescente de ações de apoio ao professor na busca e seleção de recursos multimídia adequados à realidade da disciplina para que haja um real incremento e estímulo à aprendizagem dos estudantes no uso desse sistema. 


\section{Nota}

1 Tutores de apoio ao professor (TAP) são bolsistas do Departamento de Mídias Digitais da Fundação Cecierj que atuam no apoio à implementação de novas tecnologias para EaD junto aos docentes do Consórcio CEDERJ. Para melhor entendimento das funções dos TAPs no modelo de difusão de tecnologias do Consórcio CEDERJ, consulte o artigo de Salvador, Rolando, Almeida, Mello \& Bielschowsky publicado nesta mesma edição especial da Revista EAD em Foco.

\section{Referências bibliográficas}

Epstein, J. (2002). O negócio do livro: passado e futuro do mercado editorial. $1^{a}$ ed. Rio de Janeiro: Record.

Johnson, L. et al. (2011). The 2011 Horizon Report. Austin, Texas: The New Media Consortium. Disponível em http://wp.nmc.org/horizon2011

Mattar,J. (2009). Youtube na educação: o uso de vídeos em EAD. Disponível em http://www.joaomattar.com/YouTube\%20na\%20Educa\%C3\%A7\%C3\%A30\%20 o\%20uso\%20de\%20v\%C3\%ADdeos\%20em\%20EaD.pdf

Mattar,J. (2012). Tutoria e interação em educação a distância. São Paulo: Cengage Learning.

Mantilla, S. P. S., Fonseca, C. A. S.,Alves, N. C.\& Perdigão, L. T. (2014). Objetos virtuais de aprendizagem para o curso de Ciências Biológicas do Consórcio Cederj: produção e uso de REAs. In: XVI Encuentro Iberoamericano de Educacion Superior a Distância. Rio de Janeiro. (no prelo).

Salvador, D. F., Rolando, L. G. R., Almeida, C. M., \& Mello, J. A. (2014). Mudança de cultura no uso de tecnologias educacionais: estudo de caso no modelo semipresencial do Cederj. In: XVI Encuentro Iberoamericano de Educacion Superior a Distância. Rio de Janeiro. (no prelo).

Moore, Michael \& Kearsley, Greg.(2007). A educação a distância: uma visão integrada. Trad. Roberto Galman. São Paulo: Thomson Learning. 
Nicola, L. B. \& Rodrigues, A. P.(2001). Objetos de aprendizagem como potencializadores no estudo da biologia. Novas Tecnologias na Educação, 9 (1), 1-10. 